\title{
Suppression of Food Intake by Apolipoprotein A-IV Is Mediated through the Central Nervous System in Rats
}

\author{
Kazuma Fujimoto, * Koji Fukagawa, ${ }^{*}$ Toshiie Sakata, ${ }^{\star}$ and Patrick Tso* \\ * Departments of Physiology, Louisiana State University Medical Center, Shreveport, Louisiana 71130; \\ and ${ }^{\ddagger}$ Department of Internal Medicine I, Medical College of Oita, Oita 879-55, Japan
}

\begin{abstract}
The aim of this experiment was to investigate whether the anorectic effect of apolipoprotein A-IV (apo A-IV) after lipid feeding is mediated via the central nervous system. Infusion of 0.5 $\mu \mathrm{g}$ of apo A-IV into the third ventricle failed to suppress food intake. Higher doses ( $1 \mu \mathrm{g}$ or higher) of apo A-IV infused into the third ventricle inhibited food intake in a dose-dependent manner. In contrast, when apo A-I was infused into the third ventricle it had no effect on food intake. To further test the hypothesis that apo A-IV is an important factor controlling food intake, we administered goat anti-rat apo A-IV serum into the third ventricle of rats that were allowed food and water ad lib. In all rats tested, this treatment resulted in enhanced food intake. In contrast, infusion of goat anti-rat apo A-IV serum failed to elicit such a response. Lastly, we determined the apo A-IV concentration in plasma and cerebrospinal fluid before and during active lipid absorption. Apo A-IV concentration in cerebrospinal fluid was about 1 / 20 that of plasma. Both serum and cerebrospinal fluid apo A-IV increased markedly as a result of feeding of lipid. In conclusion, we propose that apo A-IV may act centrally to control food intake. (J. Clin. Invest. 1993. 91:1830-1833.) Key words: lipid • satiety factor • apolipoprotein A-IV • intestinal lipid absorption • chylomicron • third ventricle $\bullet$ central nervous system
\end{abstract}

\section{Introduction}

Apolipoprotein A-IV (apo A-IV) is a protein associated with lipoproteins (1) and is produced exclusively by the human small intestine (2). Although apo A-IV was discovered many years ago ( 3 ) and its cDNA sequence was reported by Boguski et al. (4), its physiological function has remained unclear until recently. Apo A-IV synthesis by the small intestine increases markedly after the ingestion of lipid, and this results in a marked increase in apo A-IV output in mesenteric lymph (5, 6 ). It has been demonstrated that this increase in biosynthesis

Address correspondence to Patrick Tso, Ph.D., Department of Physiology, Louisiana State University Medical Center, 1501 Kings Highway, Shreveport, LA 71130.

Received for publication 16 July 1992 and in revised form 1 November 1992.

J. Clin. Invest.

(c) The American Society for Clinical Investigation, Inc. $0021-9738 / 93 / 04 / 1830 / 04 \$ 2.00$

Volume 91, April 1993, 1830-1833 and secretion of apo A-IV by the small intestine after fat feeding is triggered by the formation and secretion of intestinal chylomicrons $(5,7)$. We have recently shown that the apo A-IV appearing in mesenteric lymph after a lipid meal suppresses food intake, thus suggesting that apo A-IV may act as a satiety factor that circulates in the blood after fat feeding (8).

Feeding behavior is influenced by many circulating chemical factors, and chemosensitive monitoring systems for these factors exist both in the central nervous system and in peripheral organs (9-11). In order to determine whether the anorectic effect of apo A-IV might be mediated centrally, we conducted the following experiments: $(a)$ to determine the effect of infusion of apo A-IV into the third ventricle and its effect on food intake after re-feeding in $24 \mathrm{~h}$ fasted rats, $(b)$ to determine if the infusion of antiserum against apo A-IV into the third ventricle elicits a feeding response in rats that have access to food and water ad lib, and $(c)$ to determine the concentration of apo A-IV in cerebrospinal fluid during fasting and whether it increases during fat feeding.

\section{Methods}

\section{Experiment 1: Effect of apo A-IV infusion into third} ventricle on feeding behavior

Animals. Male Sprague Dawley rats (280-320 g) were housed in a room illuminated from 06:00 to 18:00 hours ( $12 \mathrm{~h}$ light-dark cycle) and maintained at $21 \pm 1^{\circ} \mathrm{C}$. The rats were allowed ad lib both tap water and powdered laboratory chow (Laboratory chow 5001; Ralston-Purina, Inc., St. Louis, MO).

Surgery. The rats were equipped with an infusion cannula in the third ventricle. Under sodium pentobarbital anesthesia $(50 \mathrm{mg} / \mathrm{kg}$ i.p.), the rats were fixed in a stereotaxic apparatus. A 15-mm-long (23gauge) stainless steel cannula was chronically implanted into the third ventricle as described before (12). The rats from both kinds of surgery were allowed to recover for five days before the experiment. All rats were handled for $5 \mathrm{~min}$ daily before the experiment to equilibrate their arousal levels.

Experimental design. In the feeding study, food was removed $24 \mathrm{~h}$ before the experiment, but free access to water was allowed. Six groups of rats were studied. Animals in groups 1-6 had indwelling infusion cannulae in their third ventricle. In groups 1-4, apo A-IV, dissolved in $10 \mu \mathrm{l}$ of physiological saline, was infused into the third ventricle at doses of $0.5,1.0,2.0$, and $4.0 \mu \mathrm{g}$ per animal. To determine whether apo A-IV's effect on food intake is specific, we infused apo A-I ( $4 \mu \mathrm{g}$ dissolved in $10 \mu$ of saline) into the third ventricle as a control (group 5). To control for the effect of vehicle (saline) infusion, another group of rats (group 6) received third ventricular infusion of physiological saline only. The infusion rate was $1 \mu \mathrm{l} / \mathrm{min}$ for $10 \mathrm{~min}$, and infusions were administered under unrestrained and unanesthetized conditions (12, 13) beginning $10 \mathrm{~min}$ before refeeding. After $24 \mathrm{~h}$ of fasting, each rat 
was re-fed at 13:00 hours and powdered food consumption was measured at $30 \mathrm{~min}$ and $60 \mathrm{~min}$ as described earlier (8).

To determine if third ventricular infusion of apo A-IV affects only food intake, water intake was determined in an additional group of rats $(n=5)$ after ventricular infusion of $4.0 \mu \mathrm{g}$ of apo A-IV. Control rats were infused with saline only. In these rats, both water and food were withheld for $24 \mathrm{~h}$ because water consumption is affected by changes in food intake (14). Infusion of Apo A-IV started $10 \mathrm{~min}$ before the animal was allowed water at 13:00 hours. Water consumption was measured at $30 \mathrm{~min}$ and $60 \mathrm{~min}$.

Purification of apo A-IV. Apo A-IV was purified by preparative polyacrylamide gel electrophoresis as described before (5). The purity of the apo A-IV was verified by analytical polyacrylamide gel electrophoresis as described previously $(5,8)$.

\section{Experiment 2: Effect of infusion of apo A-IV antiserum into} the third ventricle on feeding behavior

Animals. Male Sprague Dawley rats (280-320 g) were conditioned as described in experiment 1.

Surgery. Under sodium pentobarbital anesthesia ( $50 \mathrm{mg} / \mathrm{kg}$ i.p.), a stainless steel cannula was implanted in the third ventricle as described in experiment 1 . The rats were allowed to recover for $5 \mathrm{~d}$ before the experiment. All rats were handled for $5 \mathrm{~min}$ daily before the experiment to accustom them to experimental procedures.

Experimental design. Experiments were performed 1 wk after surgery to allow full recovery from surgical trauma. The animals were allowed food and water ad lib. Goat anti-rat apo A-IV serum ( $28 \mu \mathrm{g}$ of protein in $10 \mu \mathrm{l}$ of vol ) was infused into the third ventricle at a rate of 1 $\mu \mathrm{l}$ per min. The purity of the apo A-IV antiserum was tested by Western blot analysis as described before (5). The antibody was found to be monospecific and only reacted with apo A-IV and not the other rat apolipoproteins. The entire infusion took $10 \mathrm{~min}$, starting at 11:00 hours. This time period was chosen because this is about midway through the light period, and rats normally would not be expected to eat at this time. As a control, goat anti-rat apo A-I serum $(28 \mu \mathrm{g}$ of protein in $10 \mu \mathrm{l}$ of vol) was infused into the third ventricle at the same rate. A saline control group was also studied. Feeding and drinking behavior were observed for $60 \mathrm{~min}$.

\section{Experiment 3: Determination of serum and cerebrospinal} fluid apo A-IV content during fasting and lipid feeding

Animals. Male SD rats (280-320 g) were used. A cannula was chronically implanted into the third ventricle of the rats, as described in experiment 1 . The animals were allowed five days to recover from the third ventricular cannulation. Under halothane anesthesia, a silicon infusion tube (o.d. $1.6 \mathrm{~mm}$ ) was introduced $\sim 2 \mathrm{~cm}$ down the duodenum through the fundus of the stomach. Postoperatively, the animals were infused intraduodenally at $3 \mathrm{ml} / \mathrm{h}$ with a saline-glucose solution containing $145 \mathrm{mM} \mathrm{NaCl}, 4 \mathrm{mM} \mathrm{KCl}$, and $0.28 \mathrm{M}$ glucose, and were allowed to recover in restraining cages for $24 \mathrm{~h}$. Before lipid infusion (fasting), blood was collected from the orbital sinus, and cerebrospinal fluid collected from the indwelling ventricular cannula. Afterward, a lipid emulsion containing $40 \mu \mathrm{mol}$ glycerol trioleate, $7.8 \mu \mathrm{mol}$ egg phosphatidylcholine and $57 \mu \mathrm{mol}$ sodium taurocholate in $3 \mathrm{ml}$ phosphate-buffered saline ( $\mathrm{pH}$ 6.4) was infused intraduodenally at a constant rate of $3 \mathrm{ml} / \mathrm{h}$ for $8 \mathrm{~h}$. Blood and cerebrospinal fluid were again collected during the 8th $\mathrm{h}$ of lipid infusion. Serum and cerebrospinal fluid apo A-IV concentration was determined by electroimmunoassay as described before (5).

\section{Statistical analysis}

Data from the feeding study conducted in experiment 1 were evaluated using one-way analysis of variance, and multiple comparisons were carried out using the method of least significant difference. Differences were considered significant when the probability of the difference occurring by chance was less than 5 in $100(P<0.05)$. In experiment 2 , comparison between incidence of feeding (expressed as elicited/tested) after infusion into the third ventricle either goat anti-rat A-IV serum or goat anti-rat A-I serum was evaluated by the Fisher exact probability test. In experiment 3 , comparison of plasma and cerebrospinal fluid apo A-IV concentration during fasting and lipid feeding was evaluated by Student's $t$ test.

\section{Results}

\section{Experiment 1: Effect of infusion of apo A-IV in the third ventricle on food intake}

Table I summarizes the food intake after re-feeding in 24-hfasted rats. Infusion of $0.5 \mu \mathrm{g}$ of apo A-IV into the third ventricle failed to suppress food intake, but the infusion of apo A-IV at doses $\geq 1 \mu \mathrm{g}$ produced a significant and dose-dependent inhibition of food intake $(P<0.01$ for each comparison between apo A-IV-infused and saline-control animals) during the first 30 min of re-feeding. This suppression of food intake by apo A-IV was not observed in the following $30 \mathrm{~min}$. Fig. 1 shows the linear relationship between the food intake in grams during the first $30 \mathrm{~min}$ after re-feeding vs. the logarithm of the $\mu \mathrm{g}$ of apo A-IV infused per rat $(r=0.98, P<0.01)$. In contrast to apo A-IV, apo A-I had no effect on food intake (Table I). No adverse physiological reaction, including sedation, ataxia or hypothermia, was observed after the infusion of apo A-IV into the third ventricle.

Effect of the infusion of apo $A-I V$ in the third ventricle on water intake. Table II shows the water intake after resupply of water for $60 \mathrm{~min}$ in rats that were deprived of water and food for $24 \mathrm{~h}$. Water intake in both apo A-IV and control animals did not differ significantly, indicating that the infusion of apo A-IV into the third ventricle affects only food intake.

\section{Experiment 2: Effect on feeding behavior of the ventricular infusion of goat anti-rat apo AIV serum}

Incidence of feeding elicitation, latency between the beginning of ventricular infusion of goat anti-rat apo A-IV serum to the beginning of feeding, and duration of elicited feeding behavior are shown in Table III. Infusion of goat anti-rat apo A-IV serum into the third ventricle elicited feeding in all rats tested. Periprandial drinking behavior also accompanied this feeding

Table I. The Effect on Food Intake of the Infusion of Apo A-IV into the Third Ventricle

Food consumption after re-feeding $(\mathrm{g})$

$0-30 \mathrm{~min} \quad 30-60 \mathrm{~min}$

Apo A-IV

$\begin{array}{lll}0.5 \mu \mathrm{g} & 4.2 \pm 0.3 & 1.0 \pm 0.3 \\ 1.0 \mu \mathrm{g} & 2.8 \pm 0.3^{*} & 1.2 \pm 0.4 \\ 2.0 \mu \mathrm{g} & 1.3 \pm 0.2^{*} & 1.0 \pm 0.2 \\ 4.0 \mu \mathrm{g} & 0.6 \pm 0.2^{*} & 1.1 \pm 0.2 \\ \text { po A-I } & & \\ 4.0 \mu \mathrm{g} & 4.0 \pm 0.9 & 1.1 \pm 0.4 \\ \text { Saline control } & 4.4 \pm 0.4 & 1.4 \pm 0.2\end{array}$

Rats were fasted for $24 \mathrm{~h}$ before the feeding study. Apo A-IV, apo A-I or saline (total vol $=10 \mu \mathrm{l}$ ) was administered at $1 \mu \mathrm{l} / \mathrm{min}$ for $10 \mathrm{~min}$ before re-feeding. Values are expressed as mean $\pm \mathrm{SE}$. Five rats were tested in each group. ${ }^{*} P<0.01$ compared with saline controls. 


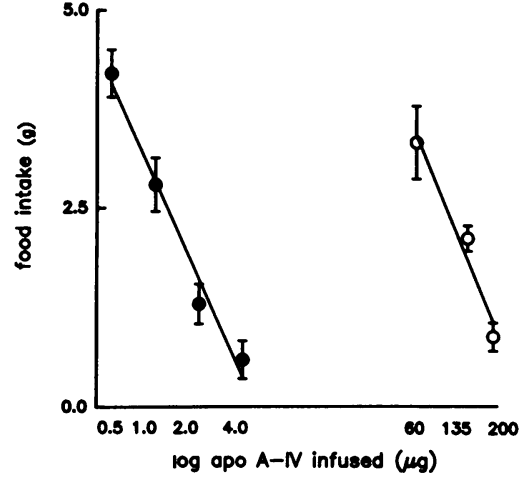

Figure 1. The relationship between the suppression of food intake during the first $30 \mathrm{~min}$ of re-feeding in 24-hfasted rats and the logarithm of the dose in $\mu \mathrm{g}$ of apo A-IV infused either into the third ventricle (closed circles) or intravenously (open circles, data derived from reference 8). Five animals were studied at each dose, and the values are expressed as mean \pm SE. Food intake diminished linearly with increasing amounts of apo A-IV infused into the third ventricle ( $Y$ $=-1.78 \log \mathrm{X}+2.84, r=0.98, P<0.01)$.

response, induced by the ventricular infusion of anti apo A-IV serum. No adverse physiological reaction such as sedation, ataxia, or hypothermia was observed. The infusion of goat antirat apo A-I serum or saline into the third ventricle failed to elicit a feeding response. The fact that the administration of apo A-IV antiserum into the third ventricle induces food intake further supports our hypothesis that apo A-IV is a potent satiety factor circulating in the bloodstream, which may regulate food intake.

Effect of fasting and fat feeding on serum and cerebrospinal fluid apo A-IV content. Fasting serum apo A-IV concentration was $119.6 \pm 6.5 \mu \mathrm{g} / \mathrm{ml}$ ( 5 animals) and it increased significantly to an average of $166.0 \pm 10.5 \mu \mathrm{g} / \mathrm{ml}$ during $8 \mathrm{th} \mathrm{h}$ of lipid infu$\operatorname{sion}(P<0.01)$. Cerebrospinal fluid has significantly lower apo A-IV content than plasma. The fasting cerebrospinal fluid apo A-IV was $5.6 \pm 0.9 \mu \mathrm{g} / \mathrm{ml}$ and increased significantly to $9.3 \pm 1.2$ $\mu \mathrm{g} / \mathrm{ml}$ during the 8th hour of lipid infusion $(P<0.01)$.

\section{Discussion}

In a previous study, we demonstrated that intravenous administration of either $2 \mathrm{ml}$ of chylous lymph (rich in apo A-IV) or $200 \mu \mathrm{g}$ of purified apo A-IV dissolved in saline significantly inhibited food intake by $75 \%$ (8). This effect was dose dependent because the infusion of $135 \mu \mathrm{g}$ of apo A-IV intravenously inhibited food intake by about $38 \%$, which was about half as effective as the infusion of $200 \mu \mathrm{g}$ of apo A-IV. The intravenous infusion of $60 \mu \mathrm{g}$ of apo A-IV was ineffective in inhibiting food intake (8). The dose of apo A-IV (200 $\mu \mathrm{g})$ infused intrave-

Table II. The Effect of Water Intake of Infusion of Apo A-IV into Third Ventricle

\begin{tabular}{lll}
\hline & \multicolumn{2}{c}{$\begin{array}{c}\text { Water consumption after resupply } \\
\text { of water }(\mathrm{ml})\end{array}$} \\
\cline { 2 - 3 } & $0-30 \mathrm{~min}$ & $30-60 \mathrm{~min}$ \\
\hline Apolipoprotein A-IV $(4.0 \mu \mathrm{g})$ & $3.9 \pm 0.6$ & $1.3 \pm 0.3$ \\
Control (Saline) & $3.5 \pm 0.3$ & $0.8 \pm 0.4$ \\
\hline
\end{tabular}

Rats were deprived of both water and food for $24 \mathrm{~h}$. Apo A-IV or saline control (total vol $=10 \mu \mathrm{l}$ ) were administered at $1 \mu \mathrm{l} / \mathrm{min}$ centrally for $10 \mathrm{~min}$ before resupply of water. Values are expressed as mean \pm SE. Five rats were tested in each group.
Table III. Feeding and Drinking Behavior during the Hour after Infusion of Either Goat Anti-Rat Apo A-IV and A-I Serum

\begin{tabular}{|c|c|c|c|c|}
\hline \multirow[t]{2}{*}{ Treatment } & \multicolumn{3}{|c|}{ Feeding } & \multirow{2}{*}{$\begin{array}{l}\text { Drinking } \\
\text { Incidence }\end{array}$} \\
\hline & Incidence & Latency & Duration & \\
\hline & & $\min$ & $\min$ & \\
\hline \multicolumn{5}{|l|}{ Goat anti-rat } \\
\hline apo A-IV & $5 / 5^{* \neq}$ & $25.9 \pm 2.3$ & $2.8 \pm 0.5$ & $3 / 5$ \\
\hline apo A-I & $0 / 5$ & ND & ND & $0 / 5$ \\
\hline Saline & $0 / 5$ & ND & ND & $0 / 5$ \\
\hline
\end{tabular}

The feeding and drinking response was measured at 11:00 hours. Five animals were studied in each group. ND, not detected. ${ }^{*} P<0.05$, compared with either apo A-I or saline; ${ }^{\ddagger}$ number of rats with elicited feeding response/number of rats tested; both feeding latency and duration are expressed as mean $\pm \mathrm{SE}$.

nously was physiological since the concentration of apo A-IV in chylous lymph varies between $80-100 \mu \mathrm{g} / \mathrm{ml}$, and lymph flow rate ranges between 3 and $4 \mathrm{ml} / \mathrm{h}$ during active lipid absorption $(5,8,15)$. The fasting apo A-IV output ranges between 60 and $100 \mu \mathrm{g} / \mathrm{h}$. Therefore the additional amount of apo A-IV released by the small intestine into the circulation during lipid absorption ranges between 100 and $300 \mu \mathrm{g}$. The effect of intravenous administration of apo A-IV on food intake is specific because the intravenous administration of 200 $\mu \mathrm{g}$ of apo A-I failed to reduce food intake.

The effect of intravenous infusion of apo A-IV on food intake might be mediated by means of its effects on peripheral organs or the central nervous system. It has been shown that there are receptors present in the liver that bind apo A-IV (16, 17). Furthermore, it has been demonstrated that apo A-IV is rapidly removed from the circulation and the major organs involved are the liver and the kidney $(18,19)$. It is presently unknown if there are apo A-IV receptors in the brain. The aim of the present study was to determine whether the effect of apo A-IV could be mediated via the central nervous system. This study clearly demonstrated that when apo A-IV was administered centrally, it suppressed food intake significantly and in a dose-dependent manner (Fig. 1). A minimum dose of $1 \mu \mathrm{g}$ of apo A-IV infused into the third ventricle was required to inhibit food intake. The cerebrospinal fluid volume of a 30-d-old rat is about $250 \mu \mathrm{l}(20)$. Since bigger rats were used in this study, we probably overestimate their cerebrospinal fluid apo A-IV content because the cerebrospinal fluid volume was probably $>250 \mu$ l. With $2 \mu \mathrm{g}$ of apo A-IV infused, the concentration of apo A-IV should be $\sim 8 \mu \mathrm{g} / \mathrm{ml}$, which is lower than the $9.3 \mu \mathrm{g} / \mathrm{ml}$ we observed in rats absorbing a physiological dose of lipid. Thus a dose of $2 \mu \mathrm{g}$ of apo A-IV infused intraventrically will result in a physiologically relevant concentration of apo A-IV in the cerebrospinal fluid. These data suggest that apo A-IV may inhibit food intake by acting on the central nervous system. It should be emphasized that when we compare the dose-response curve for peripheral vs. central administration (Fig. 1), apo A-IV is more than 50-fold more potent when administered centrally. These data suggest the possible existence of specific receptors in the central nervous system that will respond to apo A-IV. The existence of such receptors will be investigated in the future. 
The apo A-IV content of cerebrospinal fluid was significantly (20-fold) lower than that of serum, and its concentration increased significantly as a result of fat feeding (fasting versus feeding, $P<0.01$ ). The apo A-IV in cerebrospinal fluid may be synthesized de novo or derived from the circulation by filtration. Elshourbagy et al. (21) found negligible amount of apo A-IV mRNA in brain tissue, so de novo synthesis of apo A-IV in the central nervous system is unlikely. Although there are proteases present both in cerebrospinal fluid and brain tissue $(22,23)$ that will degrade any peptides that can cross the blood-brain barrier, it appears that sufficient amounts of apo A-IV may cross the blood-brain barrier to inhibit food intake centrally, particularly in view of the fact that apo A-IV administered centrally is about 50 -fold more potent that when administered intravenously. In support of the previous study (8), we also failed to observe an effect of the infusion of apo A-I into the third ventricle on food intake.

The fact that apo A-IV was infused centrally does not rule out the possibility that it was acting peripherally by leaking into the circulation. However, this is unlikely in view of our previous finding that the infusion of $60 \mu \mathrm{g}$ ( 15 times the maximum dose used in this study) of apo A-IV intravenously failed to reduce food intake. In this study, we also demonstrated that apo A-IV administered into the third ventricle has no effect on water intake nor any adverse reaction such as sedation, ataxia, or hypothermia.

The hypothesis that apo A-IV suppresses food intake via the central nervous system is further supported by the results of experiment 2 . In this study goat anti-rat apo A-IV serum was infused into the third ventricle in rats fed ad lib. The experiment was conducted at 11:00 hours (light phase) since most rats that are allowed food ad lib do not eat during this period. Administration of apo A-IV antiserum into the third ventricle elicited feeding in all animals tested $(n=5)$. In contrast, the administration of anti-rat apo A-I serum or saline into the third ventricle failed to elicit feeding. Although other possibilities exist, one likely explanation for our observation is that administration of apo A-IV antiserum in the third ventricle elicits feeding is that apo A-IV antiserum probably removes any endogenous apo A-IV present. From these studies, we propose that apo A-IV is an important factor secreted by the small intestine in response to fat feeding. The apo A-IV that enters the circulation in turn may regulate food intake by acting on the central nervous system.

The finding that apo A-IV may be a circulating factor that regulates food intake is important and may have clinical relevance to food intake and obesity. For instance, it is well established that the feeding pattern of the genetically Zucker obese rat $(\mathrm{fa} / \mathrm{fa})$ is abnormal relative to its lean littermate (24). At present, it is unknown whether the circulating apo A-IV levels differ between the Zucker obese (fa/fa) and their lean littermates ( $\mathrm{Fa} /-)$. An understanding of the synthesis and secretion of apo A-IV in the Zucker obese rat may help us understand the etiology of the eating disorder and obesity in these animals.

\section{Acknowledgments}

We are indebted to Professor Trevor G. Redgrave from the University of Western Australia for helpful suggestions and Drs. D. Neil Granger, Karen Crissinger, Ted Kalogeris and Tak Yee Aw for reading the manuscript. We are grateful to Ms. Tomoko Fujimoto, Ms. Laura Gray, and Ms. Traci Johnston for their skillful technical assistance.
This work was supported by research grants from National Institutes of Health DK-32288 and also the Center of Excellence in Arthritis and Rheumatology. Dr. P. Tso is the recipient of a Career Development Award DK 01575.

\section{References}

1. Tso, P. 1985. Gastrointestinal digestion and absorption of lipid. Adv. Lipid Res. 21:143-186.

2. Sherman, J. R., and R. B. Weinberg. 1988. Serum apolipoprotein A-IV and lipoprotein cholesterol in patients undergoing total parenteral nutrition. Gastroenterology. 95:394-401.

3. Swaney, J. B., F. Braithwaite, and H. A. Eder. 1977. Characterization of the apolipoproteins of rat plasma lipoproteins. Biochemistry. 16:271-278.

4. Boguski, M. S., N. Elshourbagy, J. M. Taylor, and J. I. Gordon. 1984. Rat apolipoprotein A-IV contains 13 tandem repetitions of a 22-amino acid segment with amphipathic helical potential (full-length cDNA cloning/lipid-binding domains/lechitin:cholesterol acyltransferase activation/gene structure and evolution). Proc. Natl. Acad. Sci. USA. 81:5021-5025.

5. Hayashi, H., D. F., Nutting, K. Fujimoto, J. A. Cardelli, D. Black, and P. Tso. 1990. Transport of lipid and apolipoproteins A-I and A-IV in intestinal lymph of the rat. J. Lipid Res. 31:1613-1625.

6. Krause, B. R., C. H. Sloop, C. K. Castle, and P. S. Roheim. 1981. Mesenteric lymph apolipoproteins in control and ethinyl estradiol-treated rats: a model for studying apolipoproteins of intestinal origin. J. Lipid Res. 22:610-619.

7. Apfelbaum, T. F., N. O. Davidson, and R. M. Glickman. 1987. Apolipoprotein A-IV synthesis in rat intestine: regulation by dietary triglyceride. Am. J. Physiol. 252:G662-G666.

8. Fujimoto, K., J. A. Cardelli, and P. Tso. 1991. Increased apolipoprotein A-IV in rat mesenteric lymph after lipid meal acts as a physiological signal for satiation. Am. J. Physiol. In press.

9. Bray, G. A., D. A. York, and J. S. Fisler. 1989. Experimental obesity: a homeostatic failure due to defective nutrient stimulation of the sympathetic nervous system. Vitam. Horm. 45:1-125.

10. Oomura, Y., and H. Yoshimatsu. 1984. Neural network of glucose monitoring system. J. Auton. Nerv. Syst. 10:359-372.

11. Novin, D., R. C. Rogers, and G. Hermann. 1981. Visceral afferent and efferent connections in the brain. Diabetologia. 20:331-336.

12. Fujimoto, K., T. Sakata, T. Shiraishi, K. Kurata, K. Terada, and H. Etou. 1986. Anorexia induced in rat by D-glucosamine deoxidized at C-1. Am. J. Physiol. 251:R481-R491.

13. Sakata, T., M. Fukushima, K. Tsutsui, K. Arase, and K. Fujimoto. 1982. Theophylline disrupts diurnal rhythms of humoral factors with loss of meal cyclicity. Physiol. \& Behav. 28:641-647.

14. Fujimoto, K., T. Sakata, K. Ookuma, M. Kurokawa, A. Yamatodani, and H. Wada. 1990. Hypothalamic histamine modulates adaptive behavior of rats at high environmental temperature. Experientia (Basel). 46:283-285.

15. Tso, P., K. L. Buch, J. A. Balint, and J. B. Rodgers. 1982. Maximal lymphatic triglyceride transport rate from the rat small intestine. Am. J. Physiol. 242:G408-G415.

16. Ghiselli, G., W. L. Crump III, and A. M. Gotto. 1986. Binding of apo A-IV-phospholipid complexes to plasma membranes of rat liver. Biochem. Biophys. Res. Commun. 139:122-128.

17. Dvorin, E., N. L. Gordon, D. M. Benson, and A. M. Gotto, Jr. 1986. Apolipoprotein A-IV. A determinant for binding and uptake of high density lipoproteins by rat hepatocytes. J. Biol. Chem. 261:15714-15718.

18. Dallinga-Thie, G. M., F. M. Van't Hooft, and A. Van Tol. 1986. Tissue sites of degradation of high density lipoprotein apolipoprotein A-IV in rats. Arteriosclerosis. 6:277-284.

19. Ghiselli, G., W. L. Crump III, R. Musanti, B. C. Sherril, and A. M. Gotto, Jr. 1989. Metabolism of apolipoprotein A-IV in rat. Biochim. Biophys. Acta. 1006:26-34.

20. Bass, N. H., and P. Lundborg. 1973. Postnatal development of bulk flow in the cerebrospinal fluid system of the albino rat: clearance of carboxyl- $\left[{ }^{14} \mathrm{C}\right]-$ inulin after intrathecal infusion. Brain Res. 52:323-332.

21. Elshourbagy, N. A., M. S. Boguski, W. S. L. Liao, L. S. Jefferson, J. I. Gordon, and J. M. Taylor. 1985. Expression of rat apolipoprotein A-IV and A-I genes: mRNA induction during development and in response to glucocorticoids and insulin. Proc. Natl. Acad. Sci. USA 82:8242-8246.

22. Hambrook, J. M., B. A. Morgan, M. J. Rance, and C. F. C. Smith. 1976. Mode of deactivation of the enkephalins by rat and human plasma and rat brain homogenates. Nature (Lond.). 262:782-783.

23. Griffiths, E. C., and J. A. Kelly. 1979. Mechanisms of inactivation of hypothalamic regulatory hormones. Mol. Cell. Endocrinol. 14:3-17.

24. Fukagawa, K., T. Sakata, H. Yoshimatsu, K. Fujimoto, and T. Shiraishi. 1988. Disruption of light-dark cycle of feeding and drinking behavior, and ambulatory activity induced by development of obesity in the Zucker rat. Int. J. Obesity. 12:481-490. 